\title{
UMA ENCICLOPÉDIA COMUM E IMPOSSÍVEL ${ }^{1}$
}

\author{
A common and impossible encyclopedia
}

\author{
Eduardo Jorge de Oliveira \\ Universidade de Zurique. Zurique, Suíça. \\ Email: posedu@gmail.com
}

EDITOR-CHEFE:

Gerson Roberto Neumann

EDITOR EXECUTIVO:

Regina Zilberman

SUBMETIDO: 30.04 .2021

ACEITO: 15.06 .2021

\section{COMO CITAR:}

OLIVEIRA, Eduardo Jorge de. Uma enciclopédia comum e impossível. Revista Brasileira de Literatura Comparada, v. 23 , n. 44 , p. $270-273$, set.dez., 2021. doi: https:// doi.org/10.1590/2596$304 \times 20212344$ eje http:// www.scielo.br/rblc https://revista.abralic.org.br o abrir a Pequena enciclopédia de seres comuns, de Maria Esther Maciel, Lo leitor depara-se com o seguinte aviso:

Este livro talvez não exista. Ou melhor: sua inexistência é o que, provavelmente, o justifica enquanto livro. Foi escrito por uma bióloga que não é bióloga, mas finge ser uma, na medida do impossível.Já os seres vivos nele incluídos - todos classificados segundo certas peculiaridades de seus nomes comuns - têm uma realidade irrefutável: seja pela ciência, pela literatura ou por nenhuma das duas $(2021$, p. 5).

E, portanto, o livro existe. Maria Esther Maciel elaborou um paratexto que faz justiça às narrativas de Borges, isto é, pode-se admitir que o livro existe e não existe, pois o leitor pode ter em nas mãos apenas uma versão do livro ou, quando muito, uma variante das invenções enciclopédicas das quais a autora encarna o papel de uma agente que coleta informações exatas. Digamos que o livro admita sua existência e sua não existência. Com isso, promove um recorte de um universo muito mais vasto. Vejamos um exemplo que se divide em duas partes: por um lado, Maria Esther Maciel reflete brilhantemente sobre coleções, enciclopédias, taxonomias; ela dedicou livros ao assunto como o A memória das coisas: ensaios de Literatura, Cinema e Artes Plásticas, de 2004, e As ironias da ordem - coleções, inventários e enciclopédias, de 2010; e, por outro, a autora parodia a rigidez com qual as ínfimas e infinitas noções da vida entram nos critérios, nas metodologias, enfim, nos rigores da ciência. Também em 2004, Maria Esther Maciel publicou $O$ livro de Zenóbia e, agora, em um gesto de quem parodia a si mesma, ela nos apresenta a Pequena enciclopédia de seres comuns, dedicado à Zenóbia, "minha zoóloga/botânica de estimação".

Antes de entrar nos seres comuns, caberia situar em algumas palavras a noção de livro na obra de Maria Esther Maciel, pois ela joga com os seus dois ofícios reais, a saber, o de professora e de escritora, e os imaginários,

\footnotetext{
${ }^{1}$ Resenha de: MACIEL, Maria Esther. Pequena enciclopédia de seres comuns. São Paulo: Todavia, 2021.
} 
o de zoóloga e bióloga. Sem entrar propriamente no jogo biográfico e autobiográfico, a noção de livro na obra de Maria Esther aproxima-se de um labirinto de espelhos no qual os saberes, por mais que sejam extremamente exatos, se deformam quando se refletem em texto literário. Eis que a literatura não apenas transmite um saber sobre ela mesma, mas expõe os limites da razão classificatória. Fato que não acontece sem humor. As classificações de Pequena enciclopédia de seres comum dividem-se em quatro partes: Marias, Joões, Viúvas e viuvinhas, e Híbridos. Às partes do livro, acrescenta-se outro paratexto cujo título ET CETERA expõe o livro a infinidade de possibilidades que implica recombinar seja os animais existes na presente publicação, seja aqueles que ainda não foram inventados. No entanto, antes de explorar a potência do ET CETERA, cabe visitar concretamente quatro seres, um de cada categoria. Nesta breve leitura são eles: Maria-Cavaleira (Myiarchus ferox), João-Baiano (Synallaxis cinerea), Viuvinha-de-óculos (Hymenops perspicillatus) e a Trepadeira-elefante (Argyreia nervosa). Em meio aos mais diversos seres, nessa seleção estão três pássaros e uma espécie de planta com a qual a autora encerra a quarta parte do livro. Caberia acrescentar ao rigor das ciências imaginárias de Maria Esther Maciel a atividade de ornitóloga, pois ela sabe muito bem como descrever e combinar os saberes sobre as aves e pássaros. O primeiro exemplo é o de Maria Cavaleira:

Ela só canta alto nas sextas-feiras. Em geral, seu som é um chamado ligeiro. De bico negro, tem cauda longa e dorso preto, garganta cinza e algumas claridades nas asas quando voa. Não esconde seu gosto pelos espaços abertos do cerrado, onde se sente em casa. Seu topete se eriça de vez em quando, sobretudo quando fica brava. Captura moscas com vontade e não sem ferocidade. Seu canto, dizem, é um brií delicado, e poucas pessoas conseguem identificá-lo. Apenas as crianças - e quando muito pequenas entendem o que essa maria fala (2021, p. 18).

A descrição cuidadosa no comportamento solicita da autora uma imaginação etológica, isto é, que seja capaz de conhecer o comportamento animal, inserindo-o ainda em um ambiente específico, o cerrado brasileiro. Além disso, o contato comunicativo interespécie entre humano e não-humano só ocorre entre crianças que, por serem muito pequenas, permitem que se deduza que elas não têm acesso aos atos de fala e que nesse processo, estamos excluídos de uma conversa. Ainda pela ornitologia da autora, o leitor e a leitora podem, cuidadosamente, observar uma espécie em extinção como o JoãoBaiano. E do cerrado seguimos à Mata Atlântica:

De dorso cinzento, possui manchas laranja no topete, nas asas e na cauda. É uma ave ágil, que usa seus talentos acrobáticos para a captura de insetos. Habita regiões altas, aprecia galhos e cascas de árvores solitárias e possui olhos um tanto ásperos. Espécie em perigo, ainda é encontrável na Mata Atlântica, entre o sul da Bahia e o nordeste mineiro, em famílias pequenas ou aos pares. Sabe-se que seu espaço tem sido, aos poucos, transformado em pastagem, e isso o deixa com o coração amargurado. Seu canto contínuo e repetido parece, às vezes, desafinado, mas não compromete em nada o seu charme (2021, p. 37).

A autora move-se pelas mais distintas partes do país e, desta vez na Mata Atlântica, apresenta um pássaro muito específico. Na própria literatura brasileira, Mário de Andrade, que tinha um ouvido e conhecimento musical apuradíssimo, observou nos seus escritos sobre a música brasileira que os olhos são mais ásperos que os ouvidos. Esse parece ser o caso do João-Baiano, cujo canto desafinado e coração amargurado não deixa de se relacionar com João Gilberto. Se lido sob esse aspecto, pode-se dizer que existe uma "bossa nova” na natureza. A terceira ave é a Viuvinha-de-óculos, cujo canto pode ser um apelo ou um chamado: 
Habita áreas úmidas, como brejos e juncais. Perspicaz, corre entre os bancos de lama, à caça de insetos menos atentos. Com uma auréola ao redor dos olhos, é como se usasse óculos ou uma máscara amarela. Quando voa, deixa ver a cor branca que se oculta sob as asas. Se macho, é negra. Se fêmea, é parda e cheia de estrias. Seu canto é um apelo, quase um chamado. Não se sabe como ela enxerga o mundo, mas uma coisa é certa: no que vê, ela distingue o que é perigo e o que a acolhe de fato. São olhos são exatos (2021, p. 63).

Os olhos exatos da Viuvinha-de-óculos interpelam a inteligência do olhar animal, pois eles não se isolam de seu ambiente. A perspicácia de uma Viuvinha-de-óculos, por exemplo, não viria sem a presença dos brejos e juncais, terreno úmido e difícil para que a vida animal seja por demasiado simplificada. Uma ave como esta percebe um mundo úmido, brejeiro e tem um pensamento-movimento flexível como um junco. Pelo menos é o que poderia ser acrescentado à lápis na página por algum ornitólogo amador. Saindo do âmbito ornitológico e fazendo uma breve passagem pelas vidas vegetais, convém citar a "Trepadeira-elefante", sobretudo porque ela é uma planta que possui uma beleza estranha:

É uma planta vigorosa. De ramagem longa e raízes profundas, sobe pelos caramanchões, muros e cercas. Uma fina penugem aveludada cobre os ramos e a parte inferior de sua folhagem. Por isso o seu verde adquire um tom prateado. Dá flores em forma de orelha de elefante, o que legitima sua ligação com o paquiderme. Mas o que nela mais atrai os humanos são os efeitos alucinógenos de suas sementes, consideradas sagradas graças a seus poderes xamânicos. Entretanto, como nem tudo é perfeito, ela está sempre com os nervos à flor da pele. Lenhosa e manhosa, odeia geadas e se aconchega ao calor úmido dos solos férteis (2021, p. 104).

A planta possui uma beleza estranha talvez pelas antípodas que anulariam sua existência: as raízes profundas e o movimento que "escala" muros, cercas e caramanchões poderia intrigar a comunidade de biólogos. Suas flores são capazes de intrigar aquelas e aqueles que se maravilham com a estrutura reprodutiva das angiospermas, composta geralmente pelo cálice, pela corola e pelos estames. Retornando à estrutura "flor", temos a forma de orelha de elefante, o que se assemelha a uma grande folha. Em meio a este sutil jogo de semelhanças convém ressaltar o contraste existente neste espécimen, cujo próprio nome, Trepadeira-elefante, mostra uma leveza e peso simultâneos.

Considerando a dimensão labiríntica dos livros de Maria Esther Maciel, convêm chamar a atenção para outro verbete do livro: a "Viuvinha humana" (Homo sapiens viuvensis) que fornece aos seus leitores uma dimensão que o filósofo Jacques Derrida chamaria de animal autobiográfico, isto é, um animal que imprime seus traços humanos no mundo. Aqui a autobiografia e a biografia inserem-se em um plano que ultrapassa a perspectiva individual, entrando muito mais no registro do que poderia ser chamada de uma escrita do luto, ou melhor, de uma formulação da perda que não deixa de ter uma energia vital e certo humor:

Ela está triste, mas não é triste. O desamparo que lhe é atribuído por outros humanos não existe senão como uma saudade doída do que foi irreversivelmente perdido. De resto, persiste e se mantém altiva. "Contra a solidão, ouvir Bach é um antídoto", uma já me disse, ao sair do luto. Outra, menos afeita às coisas líricas, me contou que o trabalho foi sua forma de recusa ao tédio inapelável dos dias. Sei, ainda, daquela que (para conter a melancolia) se rendeu às vertigens da escrita. Cada uma com seu recato. Ou sua malícia (2021, p. 66). 
Com a reelaboração do luto a partir de um verbete sobre a viuvez humana, a autora revela uma estrutura presente em todo o livro, a saber, que a diversidade das vidas produz ritmos que muitas vezes são incompreensíveis para os humanos. Com a ficção, Maria Esther Maciel atinge outra escala dos estudos animais, ela capta uma musicalidade, um ritmo que, através de suas frases, chamam a atenção para os mistérios da vida animal, vegetal e que, ao mesmo tempo, mantém um encantamento com o cotidiano. Por isso, a escala é importante: a enciclopédia é pequena. E os seres, por sua vez, são comuns. Ao contrário das zoologias fantásticas e dos seres imaginários que Jorge Luis Borges tão bem nos legou, a autora submerge na dimensão cotidiana para encontrar aí uma musicalidade animal e vegetal que emana dos seus verbetes.

A estrutura permanece aberta e, com isso, convém retornar ao ET CETERA, mais precisamente à seguinte afirmação: "Muitos outros seres poderiam ocupar suas páginas, já que as marias, os joões, as viúvas e viuvinhas, os híbridos animais e vegetais se multiplicam em diferentes reinos, famílias e espécies do mundo natural" (2021, p. 109). O livro abre a possibilidade de mutações, isto é, de outros livros que podem vir ou de mais verbetes a serem acrescidos em edições futuras. O plural de João, Joões, por exemplo, é um grande achado linguístico e mereceria um estudo a parte em termos de coletivo para o nome tão comum.

Ainda na dimensão do objeto livro, o projeto gráfico é extremamente elegante. Com a capa de Flávia Castanheira, os desenhos de Julia Panadés ultrapassam a noção de ilustração que cumpre uma função complementar ao texto. Eles são uma obra em si e que tornam o conjunto de textos e de imagens uma enciclopédia que não apenas dá um prazer visual, textual, como, juntos, tramam uma fabulação geral destes seres que, de agora em diante, habitam a literatura brasileira contemporânea. Atenção, leitoras e leitores, vocês são fundamentais na dimensão ficcional deste livro. A dimensão ficcional contida nele vai encantar o dia a dia de vocês.

\section{REFERÊNCIAS}

ANDRADE, Mário de. Ensaio sobre a música brasileira. São Paulo: Martins Editora, 1972.

DERRIDA, Jacques. L'animal que donc je suis. Paris: Galilée, 2006.

MACIEL, Maria Esther. Pequena enciclopédia de seres comuns. São Paulo: Todavia, 2021.

MACIEL, Maria Esther. Literatura e animalidade. Rio de Janeiro: Civilização Brasileira, 2016.

MACIEL, Maria Esther. As ironias da ordem: coleções, inventários e enciclopédias ficcionais. Belo Horizonte: Editora da UFMG, 2010.

MACIEL, Maria Esther. A memória das coisas: ensaios de literatura, cinema e artes plásticas. Rio de Janeiro: Lamparina, 2004. 